\title{
Oxidative Stress and Skin Fibrosis
}

\author{
Anjali Shroff $\cdot$ Andrew Mamalis $\cdot$ Jared Jagdeo
}

Published online: 17 October 2014

(C) The Author(s) 2014. This article is published with open access at Springerlink.com

\begin{abstract}
Fibrosis is defined as increased fibroblast proliferation and deposition of extracellular matrix components with potential clinical ramifications including organ dysfunction and failure. Fibrosis is a characteristic finding of various skin diseases which can have life-threatening consequences. These implications call for research into this topic as only a few treatments targeting fibrosis are available. In this review, we discuss oxidative stress and its role in skin fibrosis. Recent studies have implicated the importance of oxidative stress in a variety of cellular pathways directly and indirectly involved in the pathogenesis of skin fibrosis. The cellular pathways by which oxidative stress affects specific fibrotic skin disorders are also reviewed. Finally, we also describe various therapeutic approaches specifically targeting oxidative stress to prevent skin fibrosis. We believe oxidative stress is a relevant target, and understanding the role of oxidative stress in skin
\end{abstract}

\footnotetext{
A. Shroff

Department of Dermatology, Icahn School of Medicine at Mount Sinai, Clinical Research - Dermatology, 5 East 98th Street- 5th floor, Box 1048, New York, NY, USA

e-mail: anjalis709@gmail.com
}

\author{
A. Mamalis - J. Jagdeo \\ Department of Dermatology, University of California Davis, \\ Sacramento, CA, USA \\ e-mail: andrewmamalis@gmail.com \\ A. Mamalis · J. Jagdeo \\ Dermatology Service, Sacramento VA Medical Center, \\ Mather, CA, USA \\ J. Jagdeo $(\square)$ \\ Department of Dermatology, State University of New York \\ Downstate Medical Center, Brooklyn, NY, USA \\ e-mail: jrjagdeo@gmail.com
}

fibrosis will enhance knowledge of fibrotic skin diseases and potentially produce targeted therapeutic options.

Keywords Skin fibrosis - Skin scarring $\cdot$ Scars . Oxidative stress $\cdot$ Free radicals $\cdot$ Therapy

\section{Introduction}

Fibrosis is caused by increased tissue remodeling interrupting normal function and is a common cellular response to long-term inflammation or cell injury [1••]. Though usually a beneficial tissue response, increased fibrosis can lead to organ dysfunction and degenerative changes in vascular illnesses such as diabetes, hypertension, and chronic kidney disease [2]. The effects of fibrosis are prominent in dermatological diseases such as scleroderma, graft-versus-host disease (GVHD), keloids, and other fibrotic diseases. Fibrotic skin disorders can greatly impact patient quality of life with organ dysfunction and psychological sequelae [3••, 4-6]. Despite such serious effects, mechanisms of fibrosis are still not completely understood, and the need for anti-fibrotic treatments remains [3••].

Fibrosis is initiated by cellular injury due to prolonged injury, inflammation, infection, autoimmune reactions, allergy, radiation, or chemical damage [7, 8]. Subsequent activation of inflammatory cells, elevations of oxidative stress, uncontrolled increase in fibroblast number, and deposition of extracellular matrix (ECM) components characterizes fibrosis. Oxidative stress, an imbalance of oxygen- and nitrogen-based free radical production and the cellular antioxidant defense system, has an important role in the pathogenesis of fibrosis with effects on cellular pathways of function and repair [3••, 9]. Consequently, 
there has been increasing research into the role of oxidative stress in fibrotic skin disease.

In particular, therapeutic modalities targeting these radicals in fibrotic diseases have been of special interest. To our knowledge, there are no published reviews that primarily focus on the role of oxidative stress in skin fibrosis. In this review, we discuss the mechanisms via oxidative stress that promote skin fibrosis highlighting specific fibrotic skin disorders. We also seek to expound on a variety of potential therapeutics-particularly focusing on cellular targets and mechanisms of action.

\section{Methods}

A search of the published literature from 1 January 2009 to present on the role of oxidative stress in skin fibrosis was performed in July 2014. The following fibrotic skin disorders were identified after review of the textbook Dermatology [10•]: acral fibrokeratoma, amyloidosis, atypical fibroxanthoma, bleomycin-induced skin fibrosis, cutaneous angiofibroma, dermatofibroma, dermatofibroma protuberans, eosinophilia-myalgia syndrome (EMS), eosinophilic fasciitis, epithelioid cell histiocytoma, epithelioid sarcoma, fibroblastic rheumatism, fibroma of the tendon sheath, fibrosarcoma, fibrous hamartoma, graft-versus-host disease, hypertropic scars, infantile digital fibroma, infantile myofibromatosis, keloids, lipodermatosclerosis, mixed connective tissue disease, multinucleate cell angiohistiocytoma, nephrogenic systemic fibrosis, nodular fasciitis, porphyria cutanea tarda, restrictive dermopathy, scleredema, scleredema diabeticorum, scleroderma, scleromyxedema, sclerotic fibroma of the skin, stiff skin syndrome, superficial fascial fibromatosis, taxane-induced skin fibrosis, toxic oil syndrome (TOS), and Winchester syndrome. A search of PubMed and EMBASE was conducted using specific keywords or MeSH terms. "Fibrosis" was combined with ("oxidative stress," "reactive nitrogen species," or "reactive oxygen species") along with the above listed disorders. Papers published within the last 5 years were included. Papers in a language other than English were excluded. Additional articles were included from the bibliography of articles meeting the search criteria.

\section{Results}

As outlined in Table 1, our initial search resulted in 131 articles from the Pubmed database. A total of 131 articles were considered and screened. A title and abstract screen was conducted, exclusion of articles not in English was completed, and duplicates removed with a total of 54
Table 1 Schematic of literature search strategy and results

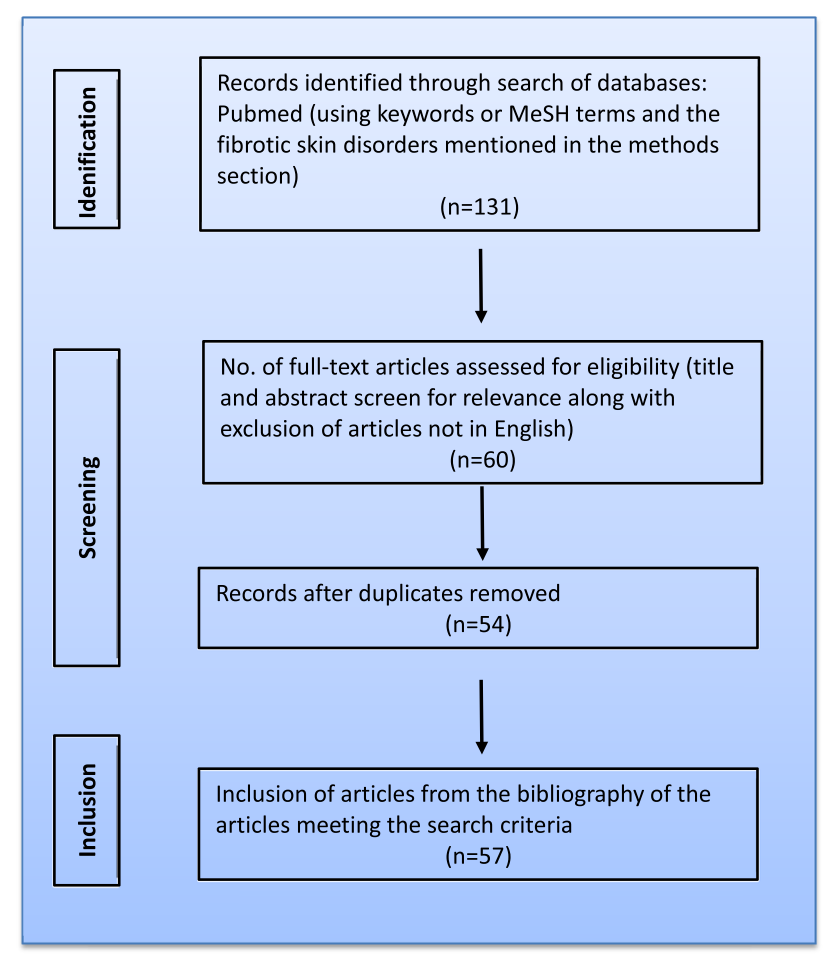

articles remaining. Additional articles from the bibliography of the articles meeting the search criteria were included with a total of 57 articles in this review.

\section{The Role of Oxidative Stress in Skin Fibrosis}

A summary of the general mechanism of fibrosis is depicted in Fig. 1. Damaged cells recruit multiple regulators of fibrosis such as cytokines, chemokines, angiogenic factors, growth factors, acute phase proteins, and caspases [8]. These regulators recruit endogenous cells such as neutrophils, macrophages, T- and B-lymphocytes that release profibrotic growth factors such as transforming growth factor beta (TGF-beta), connective tissue growth factor (CTGF/CCN2), and platelet-derived growth factor (PDGF). The activation of these agents causes synthesis of ECM via activation and differentiation of myofibroblasts from mesenchymal, epithelial, endothelial, and fibroblastlike cells $[8,11]$. In addition to the increased synthesis and deposition of ECM, alpha-smooth muscle actin ( $\alpha$-SMA), a myofibroblast-associated protein which serves to increase contraction of the matrix, and other profibrotic genes are expressed [11]. The progression of fibrosis is a complex process in which oxidative stress is required for progression. 
Fig. 1 Mechanism of Fibrosis: Damaged endothelial cells secrete chemokines that attract various immune cells. In conjunction with mediators such as reactive oxygen species and other free radicals, these immune cells increase levels of profibrotic growth factors (TGF-beta, PDGF, and CTCF)

These growth factors activate fibroblast proliferation and differentiation into myofibroblasts eventually increasing ECM deposition

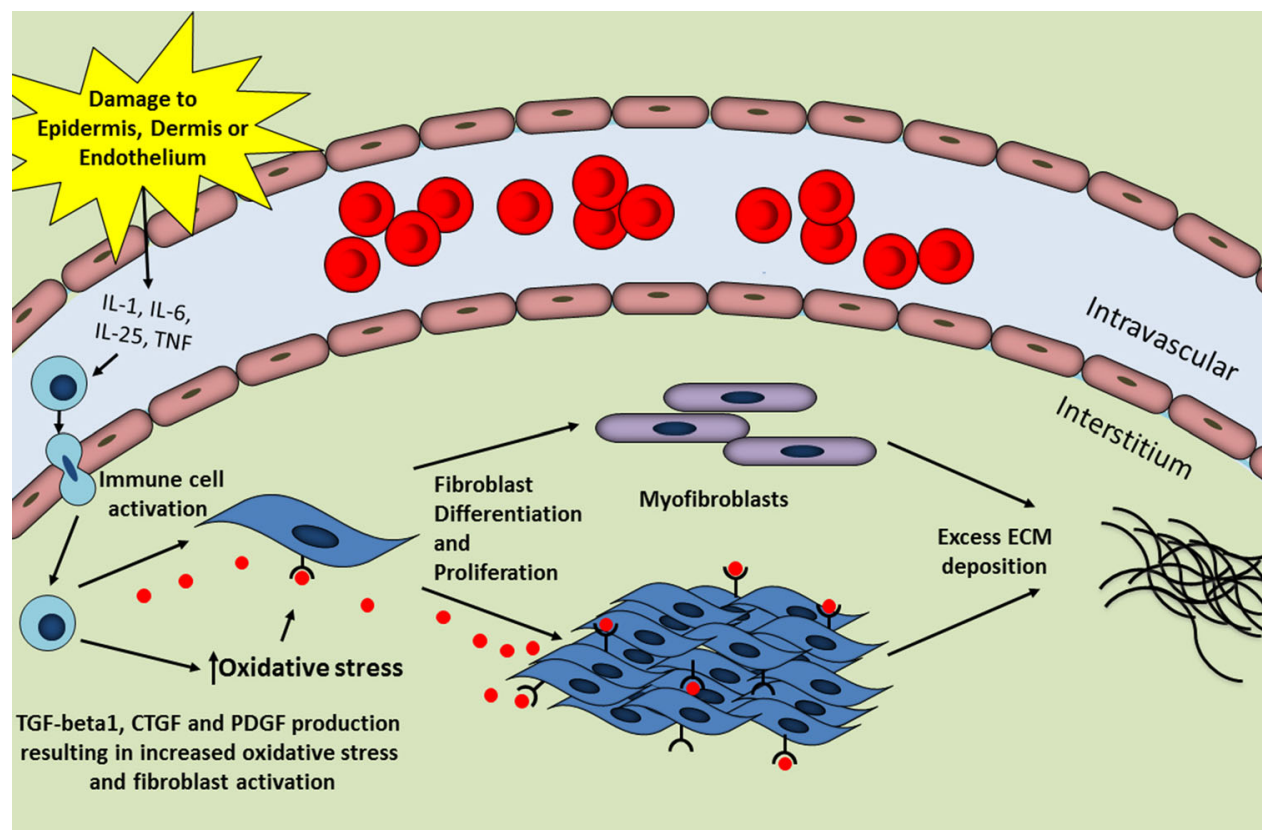

Oxidative stress is thought to play a significant role in cellular functions involved in skin fibrosis [12]. These molecules are defined as free radicals and other unstable oxygen- and nitrogen-containing molecules which have one or more unpaired electrons allowing the formation of other radicals [13]. Exogenously, free radicals are generated by environmental factors including ultraviolet radiation, pollution, cigarette smoke, and other inflammatory processes $[3 \bullet \bullet]$. Endogenously, free radicals are formed by enzyme systems including the electron transport chain activity [3••], xanthine oxidase [14], the mitochondrial respiratory chain [15], lipid peroxidases [16], cytochrome P450 [17], NO synthase [18], and multicomponent nicotinamide adenine dinucleotide phosphate (NADPH) oxidases [19•].

\section{NAPDH Oxidase (NOX) Enzymes}

Of interest in fibrosis, NADPH oxidase (Nox) enzyme complexes [20] are located in different cellular tissues and are large producers of oxidative stress $[3 \bullet \bullet, 19 \bullet]$. In humans, seven Nox enzyme complexes have been identified [20] and have been shown to play a major role in generating radicals such as the superoxide anion, hydrogen peroxide, and singlet oxygen $[13,19 \bullet, 20]$. Secondary reactive species result from the reactions of free radicals with bystander molecules, proteins, lipids, and nucleic acids [12]. These secondary reactions delineate oxidative stress as both anti-pathogenic and cell signaling molecules.
Oxidative stress has a commonly known protective role during phagocytosis of pathogens [21]; phagocytes are activated to increase free radical production via immunoglobulins, complement proteins, inflammatory cytokines, and different types of activated receptor classes [13]. After phagocyte-mediated effects, free radicals interact with antioxidants such as vitamins, glutathione, or proteins for inactivation [13]. Enzymes including superoxide dismutase (SOD), catalase, glutathione peroxidase, and peroxiredoxins also decrease oxidative stress [13]. Although the link between phagocyte radical production and fibrosis is not well defined, we anticipate this is an important area of future research.

Extracellular signaling is necessary to augment oxidative stress to facilitate their interaction with proteins, DNA, lipids, and carbohydrates. These signals act via three main intracellular signaling pathways, which cause an intracellular increase in oxidative stress along with other downstream actions. These pathways include inhibition of protein tyrosine phosphatases (PTP), activation of MAPK cascades or other kinases, and activation of specific transcription factors $[22 \bullet \cdot]$.

Interaction of cytokines or growth factors with cell receptors allows for augmentation of oxidative effects. Specific cytokines and signaling molecules such as angiotensin II, PDGF, and TGF-beta have been implicated for their pro-oxidative roles [23]. Once Nox1 and Nox2 are activated via PDGF or Nox4 via TGF-beta, oxidative stress is increased and ECM protein synthesis is modulated via subsequent activation of PTP's and activation of specific kinases such as JNK, MAPKs, JAKs, c-Src, or extracellular 
signal-regulated kinase (ERK) [3••]. This results in signal cascade phosphorylation and increased expression of transcription factors as well as fibrotic genes that increase expression of TGF-beta, CTGF (CCN2), and PDGF [1 ••, 24•]. Thus, oxidative stress has been shown to stimulate expression and secretion of these cytokines and growth factors, influencing differentiation of fibroblasts [25], profibrotic actions [26], and epithelial-mesenchymal transition (EMT) [27]. Additionally, oxidative stress has been associated with aging [28], fibrosis, and scar formation [13, 29-31]. Hence, oxidative stress is necessary for various cellular functions.

Oxidative stress acts to influence cellular fibrosis via a multitude of different cellular signaling actions within the cell. For instance, oxidative stress has been shown to affect profibrotic cytokines and pathways such as TGF-beta and mTOR, cell cycle regulation, EMT, and collagen production. Understanding the mechanisms of oxidative stress interaction with cellular fibrotic actors allows for recognition of additional anti-fibrotic therapeutic targets.

\section{Oxidative Stress and TGF-beta}

Oxidative stress is also influenced by TGF-beta. TGF-beta, a profibrotic cytokine, has been shown to regulate cellular proliferation, differentiation, and ECM production. Research demonstrates that TGF-beta activates NADPH oxidases such as Nox4, augmenting fibroblast recruitment and differentiation $[1 \bullet \bullet, 25,32,33 \bullet]$. Increased Nox expression augments free radical levels, activates the mitochondrial respiratory chain, and represses cellular antioxidant systems $[1 \bullet \bullet$. TGF-beta binding to cell surface receptors causing phosphorylation of Smad transcription factors allows for gene expression of histone acetyltransferases [34].

Mitochondrial free radicals, also increased by TGF-beta signaling, are necessary for TGF-beta-mediated gene transcription in the Smad3 pathways [34]. Within the Smad3 pathways, plasminogen activator inhibitor-1 (PAI1), a potent profibrotic matricellular protein, is important in TGF-beta1 signaling and is involved in inflammatory and fibrotic pathways $[1 \bullet \cdot, 35-40]$ via suppression of ECM degradation and increased matrix remodeling [1••, 37]. TGF-beta1 also acts via free radicals on non-Smad pathways including the c-Src-EGFR-MEK-ERK cascade. Smad and non-Smad pathways are influenced by oxidative stress within the cell and interact to increase PAI-1 expression. These pathways suggest a positive feedback loop [34] and highlight the role of oxidative stress in fibrosis. Overall, TGF-beta1 is responsible for activation of multiple oxidative stress-related genes involved in profibrotic pathways $[1 \bullet \cdot, 41-44]$.

\section{Oxidative Stress and the Cell Cycle}

Free radicals modulate $\mathrm{G} 0, \mathrm{G} 1, \mathrm{~S}, \mathrm{G} 2$, and $\mathrm{M}$ phases of the cell cycle [45•]. Cells can be influenced to transition from the quiescent (G0) to proliferative (G1, S, G2, and M) stages by free radicals acting as signaling molecules [45•]. For example, a temporary increase in pro-oxidant activity has been shown to be required in mammalian cells during the transition from G1 to S phase [45•]. Antioxidants, such as $N$-acetyl-L-cysteine (NAC) and caffeine inhibit this progression [46, 47]. Additionally, increased SOD activity promotes proliferation with increased hydrogen peroxide activity promoting quiescence in a purported mitochondrial "ROS switch" [45•, 48]. Finally, redox regulation is thought to influence cell cycle proteins such as p21, Rb, cyclin D1/CDK4-6 kinase, and CDC25 [45•].

In fibroblasts, mild elevations in free radicals have been shown to increase proliferation [45•]. However, we have also found that slight increases in oxidative stress are associated with reduced cell counts (unpublished data). Oxidative stress influences insulin-like growth factors (IGFs), AKT/PKB, and phosphoinositide 3-kinase (PI3K) pathways to activate mammalian target of rapamycin (mTOR), which is purported to be responsible for continued translation and cell growth. Influencing continued translation causes mitochondrial oxidative phosphorylation augmenting free radical production within the cell, inherently linking mTOR and free radical generation [49]. As outlined above, oxidative stress effects can be variable with seemingly antagonistic actions on both cell cycle progression and inhibition. Oxidative signaling effects on cellular apoptosis further illustrate this antagonistic phenomenon.

\section{Oxidative Signaling and Apoptosis}

Oxidative stress plays a role in regulating apoptotic proteins and pathways. P53, a tumor suppressing protein demonstrated to be sensitive to free radicals, is important in cell cycle and apoptosis regulation [50]. Generally, stressed cells are inhibited from proceeding through cellular checkpoints. These checkpoints are regulated by p 53 which remains activated if cells cannot repair the causative cellular damage. During cellular stress, free radicals can trigger p53 to induce apoptosis. Finally, p53 downregulates manganese superoxide dismutase (MnSOD), an antioxidant enzyme, thereby increasing oxidative stress [51]. Additionally, apoptosis signal-regulating kinase-1 (ASK-1), modulates apoptosis and is a serine/threonine protein kinase causing activation of the p38 and JNK pathways [52-54]. Oxidative stress inhibits caspases and proteases involved in cell death [23]. 
The counterintuitive roles of oxidative stress in both cell cycle progression and apoptosis seem to present a quandary in terms of understanding cellular responses to oxidative signaling. In actuality, cell cycle signaling initiation and cellular responses to this signaling are complex processes dependent on the free radical cellular levels, with lethal doses signaling for apoptosis while smaller amounts needed to maintain cellular function. Moreover, oxidative changes are also influenced by a myriad of other extracellular and intracellular signals and pathways all cointeracting and enforcing the cell as a complex and dynamic environment.

\section{Oxidative Stress and Fibroblast Differentiation}

The epithelial to mesenchymal transition (EMT) of fibroblasts is required for ECM deposition. Extracellular signals can be generated by various molecules and proteins including collagen, PDGF, TGF-beta, and fibroblast growth factor (FGF) to initiate EMT [22••]. Oxidative stress influences this transition in fibrotic diseases of the lung and kidney [55-57]. Matrix metalloproteinases (MMPs) exposure increases oxidative stress also stimulating differentiation [56]. Differentiated cells, called myofibroblasts, originate from fibroblasts and facilitate wound repair, smooth muscle cell actin expression, and growth factor secretion [24•, 58-60]. With chronic Nox activation and dysregulation of related signaling pathways, activated myofibroblasts, with TGF-beta signaling, differentiate causing a chronic fibrotic state. Further regulation of myofibroblast differentiation is thought to occur secondary to potential interplay between NO/cGMP and Nox4derived free radicals. Moreover, oxidative signaling with growth factors such as TGF-beta can potentially cause dedifferentiation of myofibroblasts into fibroblasts [24•]. Hence, oxidative stress induces myofibroblast differentiation and seems to play a regulatory role.

\section{Oxidative Stress and Cellular Migration and Adhesion}

Oxidative stress plays a large role in fibroblastic migration to sites of inflammation and wound healing. Via oxidative stress, Nox4 has been particularly noted to influence cellular migration [61]. Cellular oxidative stress has been shown to increase IKK (IkB kinase)/NF- $\kappa$ B and JNK/AP-1 (activator protein 1) signaling with consequences on fibroblast migration in cardiac tissue [62]. Increased adhesion is also required for fibrosis. Free radicals are implicated as signaling molecules after integrin attachment during fibroblast adhesion and spreading [63]. Integrins, transmembrane receptors that mediate cell-to-cell attachment within the ECM, have been shown in some studies to increase oxidative stress [63].

\section{Oxidative Stress and Collagen Production}

Increased oxidative stress influences collagen production, a key feature of skin fibrosis. Integrins also mediate collagen production via free radical modulated pathways. Signaling by integrin $\beta 1$ activates FAK, allowing for downstream activation of the rac1 protein leading to increased production of collagen and other profibrotic actors such as CTGF(CCN2) and aSMA [64]. CTGF(CCN2) is induced by TGF-beta1 to promote adhesion and fibrosis [65]. Oxidative stress also causes inhibition of the "cysteine switch" which modulates MMPs, proteins responsible for ECM degradation [23, 66, 67]. Hence, studies show oxidative stress plays an essential role in the pathogenesis of ECM deposition including initiation, perpetuation, and regulation of fibrosis.

\section{Oxidative Stress in Specific Skin Diseases}

As outlined above, oxidative stress-mediated actions allow for excessive collagen deposition, typifying the fibrotic phenotype. Our understanding of oxidative stress and its role in cellular signaling in fibrosis continues to expand as studies further delineate their impact on fibrotic disease with mechanisms and findings discussed in the remainder of the paper.

\section{Graft-Versus-Host Disease}

Chronic GVHD is a scleroderma-like disease occurring 2-3 months [68] after allogeneic hemopoietic stem cell transplant. Studies have highlighted the role of $\mathrm{CD}^{+} \mathrm{T}$ cells and plasmacytoid dendritic cells in producing free radicals which likely play a large role in GVHD development [69]. Free radicals increase CCL2, a ligand protein previously detected in skin fibroblasts, attracting monocytes and T lymphocytes and elevating collagen, MMP-1, and MMP-2 expression [70]. Additionally, autoantibodies may stimulate free radical production via phosphorylation of the PDGFR tyrosine receptor [3••, 71] and an increase in type I collagen gene expression [69, 71]. Though the role of these autoantibodies has not been fully elucidated, research on this topic continues. Additionally, the therapeutic potential of arsenic trioxide, a trivalent salt which causes hydrogen peroxide toxicity and depletes inherent glutathione levels, showed decreased $\mathrm{CD}^{+} \mathrm{T}$ and dendritic cells. This was seen to ameliorate symptomatology in 
murine mice; skin and visceral fibrosis as well as other autoimmune manifestations were greatly improved [69]. Finally, the organotelluride catalyst, (PHTE) [2] NQ, has been shown to have anti-fibrotic effects via a cytotoxic oxidative pathway in fibroblasts [72]. These studies help to clarify the role of oxidative stress and highlight possible therapeutic modalities which deplete inherent antioxidants and allow accumulation of lethal levels of oxidative stress to target specific disease-associated cells.

\section{Hypertrophic Scars}

Hypertrophic scars are characterized by increased collagen deposition usually caused by injuries in the deep dermis $[3 \bullet \bullet, 73]$. They are associated with a change in collagen cross-linking behavior leading to pyridinoline cross-link formation associated with hydroxylysine pathway rather than the usual allysine cross-link formation. This switch has been associated with increased oxidative stress in ex vivo human tissue specimens [74], in which pyridinoline cross-links were also demonstrated to be present in greater amounts in normal skin subjected to artificial free radical generating systems. Cross-links were also seen to be increased in hypertrophic tissues. These findings suggest free radicals may be linked to more pyridinoline in hypertrophic tissue [74]. Additionally, other studies have shown the association between oxidative stress and the apoptosis associated protein, p53, with an interest in increasing apoptotic signaling in myofibroblasts to decrease scar formation [75]. Finally, studies have examined treatment options which target oxidative stress in efforts to decrease scarring [73]. For example, a recent study of essential oil (EO) from rhizomes of Ligusticum chuanxiong showed increased free radical production and decreased MMP [76] in human dermal fibroblasts which induced apoptosis. Another compound with positive effects on wound healing includes curcumin, a polyphenol [77, 78]. Curcumin was able to induce apoptosis in human dermal fibroblasts and inhibit fibroblast-mediated contraction, all via oxidative pathways [79]. In vitro findings demonstrate that resveratrol is capable of inhibiting fibroblast function, and it may prove effective in the treatment of hypertrophic scars or keloids in vivo $[80,81]$. These compounds call for further research into the potential oxidative-associated clinical sequelae.

\section{Nephrogenic Systemic Fibrosis}

Nephrogenic systemic fibrosis (NSF) is characterized by increased skin fibrosis subsequent to magnetic resonance imaging contrast agents in patients with renal impairment
[3••]. This potentially fatal condition usually presents with joint stiffness, tightness, swelling, pain, and joint contraction with limited treatment options [82, 83]. A recent study in murine models has demonstrated free radical involvement in the pathophysiology of this disorder. Additionally, increased Nox4 expression, secondary to TGF-beta1 signaling, led to increased ECM deposition. This study demonstrates a new oxidative therapeutic target for potential treatment options.

\section{Systemic Sclerosis and Scleroderma}

Scleroderma is a connective tissue disorder with immunological, vascular, and fibrotic skin/organ sequelae secondary to increased ECM deposition. At the cellular level, much of the pathogenesis is thought to be due to increased oxidative stress [84]. Free radical production is thought to be secondary to ischemic-reperfusion injury, generation via fibroblasts and leukocytes by the Nox system, and impaired NO metabolism [85-90].

Recent studies show various new signaling pathways in scleroderma including those linking free radicals, Ras, and ERK1-2 which increased the expression of cytokines, growth factors, and their receptors [23]. One study of dermal fibroblasts from scleroderma patients asserted decreased ECM deposition and contraction after fibroblast exposure to antioxidants with oxidative stress suppression, ERK1-2, and NF-kB activity [23, 91]. Understanding these pathways helps to elucidate possible targets for future treatments. Other articles focus on new uses of existing medications such as simvastatin or propylthiouracil, which have been tentatively shown to prevent skin fibrosis and myofibroblast differentiation [92, 93]. Newer studies have also purported arsenic trioxide and (PHTE)(2)NQ, an organotelluride catalyst, which has been shown to prevent both skin and lung fibrosis in murine models of scleroderma via cytotoxic effects on fibroblasts [72, 94], further strengthening the role of oxidative stress in the pathogenesis and therapy of skin fibrosis.

\section{Therapeutic Intervention in Skin Fibrosis}

Oxidative stress can be harnessed for anti-fibrotic therapy by: (1) suppressing free radical production and hindering fibrotic pathways or (2) stimulating oxidative pathways to alter biologic function or reach lethal levels and induce cellular apoptosis. As outlined in Table 2, compounds such as NAC and edaravone execute their effects via the former mechanism with reductions in oxidative stress effects $[95,96]$. Conversely, compounds such as EO, arsenic trioxide, and PHTE use the latter mechanism and promote 
Table 2 Summary of oxidative stress-associated therapies

\begin{tabular}{|c|c|}
\hline \multicolumn{2}{|l|}{ Oxidative stress mediating therapeutics } \\
\hline $\begin{array}{l}\text { Oxidative stress-mediated anti-fibrotic } \\
\text { therapeutics }\end{array}$ & Mechanism of action \\
\hline Simvastatin, propylthiouracil & Prevention of skin fibrosis and myofibroblast differentiation \\
\hline Arsenic trioxide & Fibroblast cytotoxicity via increased oxidative stress such as $\mathrm{H}_{2} \mathrm{O}_{2}$, depletion of glutathione \\
\hline$(\mathrm{PHTE})(2) \mathrm{NQ}$ & Fibroblast cytotoxicity via increased oxidative stress \\
\hline $\begin{array}{l}\text { Essential oil (EO) from rhizomes of } \\
\text { Ligusticum chuanxiong }\end{array}$ & $\begin{array}{l}\text { Increased oxidative stress, increased caspase- } 3 \text { activity, \& decreased MMP all inducing } \\
\text { apoptosis }\end{array}$ \\
\hline Curcumin & Oxidative stress-related fibroblast apoptosis and inhibition of fibroblast-mediated contraction \\
\hline$N$-acetyl-L-cysteine & Increased SOD activity causing decreased oxidative stress \\
\hline Edaravone & Attenuation of fibrotic proteins and cytokines such as interleukin- 6 \& TGF-b1 \\
\hline Alpha-MSH & Increased SOD2 expression causing decreased oxidative stress \\
\hline Trivalent chromium & $\begin{array}{l}\text { Initial activation of caspase- } 3 \text { with oxidative stress-related apoptosis pathways with subsequent } \\
\text { cellular necrosis pathways }\end{array}$ \\
\hline 2-deoxy-D-glucose, rapamycin & Decreased oxidative DNA stress-associated proteins \\
\hline Berberine, vitamin D3, \& aspirin & Decreased oxidative stress \\
\hline Berberine \& metformin & Suppression of mTOR signaling \\
\hline Celecoxib & Antioxidant activity via targeting of DNA oxidative damage \\
\hline 3-bromopyruvate & $\begin{array}{l}\text { Suppression of normal cellular metabolic activity and oxidative phosphorylation via inhibition } \\
\text { of glycolysis }\end{array}$ \\
\hline Hyaluronate & Protective effects on oxidative DNA damage \\
\hline BMP-7 \& rapamycin & Targeting of fibroblastic EMT \\
\hline Irbesartan & Reduced fibrosis via effects on collagen synthesis \\
\hline
\end{tabular}

apoptosis via cytotoxicity. Interestingly, some compounds such as trivalent chromium only partially use these methods to decrease fibrosis with activation of caspase- 3 via oxidative stress-related apoptotic pathways seen only on initial exposure to the compound with a later switch to cellular necrosis pathways [97]. Finally, concomitant use of both of these mechanisms may fine-tune therapy. For example, curcumin, a polyphenol, was used to induce apoptosis in fibroblasts with antioxidants such as NAC used to moderate its effects [79]. In addition to these compounds, we discuss here the additional studies supporting the use of oxidative stress-associated therapeutics.

Previous studies on antioxidants such as vitamins $\mathrm{C}$ and $\mathrm{E}$ have shown little therapeutic impact on skin disorders such as scleroderma [3••, 98, 99]. In addition to NAC, edaravone, and EO as discussed above, studies have suggested a variety of compounds such as berberine, Vitamin D3, and resveratrol, and aspirin effective at reducing oxidative stress [49]. The pathways by which these compounds decrease oxidative stress and attenuate oxidative damage warrant further investigation.

More targeted approaches to treatment on specific signaling pathways have also been proposed. For example, berberine, a natural alkaloid used in Chinese and Ayurvedic medicine, has been shown to suppress mTOR signaling along with metformin, the commonly used diabetic treatment [49]. Fibroblastic EMT has also been suggested as a potential therapeutic target with antioxidants such as BMP-7, rapamycin, GDP, and TGF-beta1 as potential mediators $[1 \bullet \bullet, 100]$.

Targeting gene expression downstream of the TGFbeta1 signaling pathway could also be an option. Genes which are known to be targets of oxidative stress with downstream profibrotic consequences such as p53, EGFR, Nox4, and Smad3 are also of interest [1••]. Additionally, oxidative stress-dependent genes such as PAI-1, CCN2(CTGF), angiotensinogen, and TGF-beta1 could be used to decrease downstream ECM molecules and other associated genes $\left[1^{\bullet \bullet}\right]$. Other potential therapeutic agents which have been shown to reduce lung and kidney fibrosis are ebselen, apocynin, and DPI in murine models [1••]. In fact, simvastatin has been purported to reduce skin thickness along with its beneficial effects on pulmonary fibrosis [92]. Finally, arsenic trioxide has been asserted to improve both skin and lung fibrosis via oxidative stress-mediated killing of activated fibroblasts.

Interestingly, multiple studies in scleroderma, hypertrophic scars, and chronic GVHD have highlighted the therapeutic potential of pro-oxidative compounds. These compounds increase oxidative stress to toxic levels causing cytotoxicity and apoptosis to occur in fibroblasts. Hence, fibrotic activity is controlled and decreased. However, 
there may be benefit with combined treatments of antioxidants with other therapeutic modalities.

\section{Conclusion}

Oxidative stress has classically been known to play a major regulatory role against pathogens in the phagocytic environment. Recent studies have shown free radicals to play an important role in skin fibrosis. Continued interest in oxidative stress and its processes is necessary to fully elucidate and better treat fibrosis in fibrotic disorders such as scleroderma, GVHD, hypertrophic scars, NSF, and other skin pathologies. Antioxidant therapy continues to be of interest along with new indications for well-known medications. We believe that these and other disorders would greatly benefit from further investigation into oxidative stress signaling pathways and their role in fibrosis, with the potential to transform treatment of skin fibrosis by dermatologists.

Open Access This article is distributed under the terms of the Creative Commons Attribution License which permits any use, distribution, and reproduction in any medium, provided the original author(s) and the source are credited.

\section{Compliance with Ethics Guidelines}

Conflict of Interest Anjali Shroff, Andrew Mamalis, and Jared Jagdeo declare they have no conflicts of interest. The content is solely the responsibility of the authors and does not necessarily represent the official views of the National Institutes of Health. The project described was supported by the National Center for Advancing Translational Sciences, National Institutes of Health, through Grant No. UL1 TR000002 and linked awards TL1 TR000133 and KL2 TR000134. This material is the result of work supported with resources at the Sacramento VA Medical Center. The contents do not represent the views of the U.S. Department of Veterans Affairs or the United States Government.

Human and Animal Rights and Informed Consent This article does not contain any studies with human or animal subjects performed by any of the authors.

\section{References}

Papers of particular interest, published recently, have been highlighted as:

- Of importance

•• Of major importance

1. - Samarakoon R, Overstreet JM, Higgins PJ (2013) TGF- $\beta$ signaling in tissue fibrosis: redox controls, target genes and therapeutic opportunities. Cell Signal 25(1):264-8. This references is of importance as it highlights the role of TGF-beta in tissue fibrosis, emphasizes SMAD and non-SMAD pathways, and possible therapeutic targets within these pathways
2. Wynn TA (2004) Fibrotic disease and the $\mathrm{T}(\mathrm{H}) 1 / \mathrm{T}(\mathrm{H}) 2$ paradigm. Nat Rev Immunol 4(8):583-594

3. •• Babalola O, Mamalis A, Lev-Tov H, Jagdeo J (2013) NADPH oxidase enzymes in skin fibrosis: molecular targets and therapeutic agents. Arch Dermatol Res. This paper serves as an excellent reference of previous oxidative stress-related research in fibrosis. It serves as an excellent source in conjunction with this paper for futher understanding of oxidative stress and fibrosis

4. Mura G, Bhat KM, Pisano A, Licci G, Carta M (2012) Psychiatric symptoms and quality of life in systemic sclerosis. Clin Pract Epidemiol Ment Health 8:30-35

5. Fauerbach JA, Heinberg LJ, Lawrence JW, Munster AM, Palombo DA, Richter D et al (2000) Effect of early body image dissatisfaction on subsequent psychological and physical adjustment after disfiguring injury. Psychosom Med 62(4):576-582

6. Fauerbach JA, Heinberg LJ, Lawrence JW, Bryant AG, Richter L, Spence RJ (2002) Coping with body image changes following a disfiguring burn injury. Health Psychol 21(2):115-121

7. Vettori S, Gay S, Distler O (2012) Role of MicroRNAs in Fibrosis. Open Rheumatol J 6:130-139

8. Wynn TA (2008) Cellular and molecular mechanisms of fibrosis. J Pathol 214(2):199-210

9. Herrick AL, Matucci Cerinic M (2001) The emerging problem of oxidative stress and the role of antioxidants in systemic sclerosis. Clin Exp Rheumatol 19(1):4-8

10. • Bolognia J, Jorizzo J, Schaffer J. Dermatology. (2012) 3rd ed. St. Louis: Mosby. This text serves as a foundation and primary reference for clinical understanding of skin fibrosis

11. Moinzadeh P, Denton C, Krieg T, Black C (2012) Scleroderma. McGraw-Hill, Fitzpatrick's Dermatology in general medicine. New York

12. Lambeth JD, Krause KH, Clark RA (2008) NOX enzymes as novel targets for drug development. Semin Immunopathol 30(3):339-363

13. Bryan N, Ahswin H, Smart N, Bayon Y, Wohlert S, Hunt JA (2012) Reactive oxygen species (ROS) - a family of fate deciding molecules pivotal in constructive inflammation and wound healing. Eur Cell Mater 24:249-265

14. McNally JS, Davis ME, Giddens DP, Saha A, Hwang J, Dikalov $S$ et al (2003) Role of xanthine oxidoreductase and NAD(P)H oxidase in endothelial superoxide production in response to oscillatory shear stress. Am J Physiol Heart Circ Physiol 285(6):H2290-H2297

15. Skulachev VP (1996) Role of uncoupled and non-coupled oxidations in maintenance of safely low levels of oxygen and its one-electron reductants. Q Rev Biophys 29(2):169-202

16. Zhang R, Brennan ML, Shen Z, MacPherson JC, Schmitt D, Molenda CE et al (2002) Myeloperoxidase functions as a major enzymatic catalyst for initiation of lipid peroxidation at sites of inflammation. J Biol Chem 277(48):46116-46122

17. Fleming I, Michaelis UR, Bredenkötter D, Fisslthaler B, Dehghani F, Brandes RP et al (2001) Endothelium-derived hyperpolarizing factor synthase (Cytochrome P450 2C9) is a functionally significant source of reactive oxygen species in coronary arteries. Circ Res 88(1):44-51

18. Vásquez-Vivar J, Kalyanaraman B, Martásek P, Hogg N, Masters BS, Karoui $\mathrm{H}$ et al (1998) Superoxide generation by endothelial nitric oxide synthase: the influence of cofactors. Proc Natl Acad Sci USA 95(16):9220-9225

19. • Altenhöfer S, Kleikers PW, Radermacher KA, Scheurer P, Rob Hermans JJ, Schiffers P, et al. (2012) The NOX toolbox: validating the role of NADPH oxidases in physiology and disease. Cell Mol Life Sci 69(14):2327-43. This manuscript describes the importance of NOX in normal and disease states

20. Block K, Gorin Y (2012) Aiding and abetting roles of NOX oxidases in cellular transformation. Nat Rev Cancer 12(9):627-637 
21. Nathan C, Shiloh MU (2000) Reactive oxygen and nitrogen intermediates in the relationship between mammalian hosts and microbial pathogens. Proc Natl Acad Sci USA 97(16):8841-8848

22. • Cannito S, Novo E, di Bonzo LV, Busletta C, Colombatto S, Parola M (2010) Epithelial-mesenchymal transition: from molecular mechanisms, redox regulation to implications in human health and disease. Antioxid Redox Signal 12(12): 1383-430. This article highlights the importance of oxidative stress in epithelial-to-mesenchymal transition (EMT). It also extensively discusses signaling roles of TGF-beta, redox signaling, and redox regulation in EMT

23. Gabrielli A, Svegliati S, Moroncini G, Amico D (2012) New insights into the role of oxidative stress in scleroderma fibrosis. Open Rheumatol J 6:87-95

24. - Sampson N, Berger P, Zenzmaier C (2012) Therapeutic targeting of redox signaling in myofibroblast differentiation and age-related fibrotic disease. Oxid Med Cell Longev 2012: 458276. This paper highlights the importance of oxidative stress in myofibroblast activation and wound healing

25. Cucoranu I, Clempus R, Dikalova A, Phelan PJ, Ariyan S, Dikalov $\mathrm{S}$ et al (2005) NAD(P)H oxidase 4 mediates transforming growth factor-beta1-induced differentiation of cardiac fibroblasts into myofibroblasts. Circ Res 97(9):900-907

26. Hecker L, Vittal R, Jones T, Jagirdar R, Luckhardt TR, Horowitz JC et al (2009) NADPH oxidase-4 mediates myofibroblast activation and fibrogenic responses to lung injury. Nat Med 15(9):1077-1081

27. Rhyu DY, Park J, Sharma BR, Ha H (2012) Role of reactive oxygen species in transforming growth factor-betal-induced extracellular matrix accumulation in renal tubular epithelial cells. Transplant Proc 44(3):625-628

28. Khodr B, Khalil Z (2001) Modulation of inflammation by reactive oxygen species: implications for aging and tissue repair. Free Radic Biol Med 30(1):1-8

29. Poli G (2000) Pathogenesis of liver fibrosis: role of oxidative stress. Mol Aspects Med 21(3):49-98

30. Foo NP, Lin SH, Lee YH, Wu MJ, Wang YJ (2011) $\alpha$-Lipoic acid inhibits liver fibrosis through the attenuation of ROS-triggered signaling in hepatic stellate cells activated by PDGF and TGF- $\beta$. Toxicology 282(1-2):39-46

31. van der Vliet A (2008) NADPH oxidases in lung biology and pathology: host defense enzymes, and more. Free Radic Biol Med 44(6):938-955

32. Sturrock A, Cahill B, Norman K, Huecksteadt TP, Hill K, Sanders $\mathrm{K}$ et al (2006) Transforming growth factor-betal induces Nox4 $\mathrm{NAD}(\mathrm{P}) \mathrm{H}$ oxidase and reactive oxygen species-dependent proliferation in human pulmonary artery smooth muscle cells. Am J Physiol Lung Cell Mol Physiol 290(4):L661-L673

33. - Barnes JL, Gorin Y (2011) Myofibroblast differentiation during fibrosis: role of $\mathrm{NAD}(\mathrm{P}) \mathrm{H}$ oxidases. Kidney Int 79(9): 944-56. This article emphasizes the importance of oxidative signaling in fibrosis progression

34. Jain M, Rivera S, Monclus EA, Synenki L, Zirk A, Eisenbart J et al (2013) Mitochondrial reactive oxygen species regulate transforming growth factor- $\beta$ signaling. J Biol Chem 288(2):770-777

35. Matsuo S, López-Guisa JM, Cai X, Okamura DM, Alpers CE, Bumgarner RE et al (2005) Multifunctionality of PAI-1 in fibrogenesis: evidence from obstructive nephropathy in PAI-1overexpressing mice. Kidney Int 67(6):2221-2238

36. Czekay RP, Wilkins-Port CE, Higgins SP, Freytag J, Overstreet JM, Klein RM et al (2011) PAI-1: An Integrator of Cell Signaling and Migration. Int J Cell Biol 2011:562481

37. Eddy AA, Fogo AB (2006) Plasminogen activator inhibitor-1 in chronic kidney disease: evidence and mechanisms of action. J Am Soc Nephrol 17(11):2999-3012
38. Chuang-Tsai S, Sisson TH, Hattori N, Tsai CG, Subbotina NM, Hanson KE et al (2003) Reduction in fibrotic tissue formation in mice genetically deficient in plasminogen activator inhibitor-1. Am J Pathol 163(2):445-452

39. Hwang M, Kim HJ, Noh HJ, Chang YC, Chae YM, Kim KH et al (2006) TGF-beta1 siRNA suppresses the tubulointerstitial fibrosis in the kidney of ureteral obstruction. Exp Mol Pathol 81(1):48-54

40. Gonzalez J, Klein J, Chauhan SD, Neau E, Calise D, Nevoit C et al (2009) Delayed treatment with plasminogen activator inhibitor-1 decoys reduces tubulointerstitial fibrosis. Exp Biol Med (Maywood) 234(12):1511-1518

41. Bondi CD, Manickam N, Lee DY, Block K, Gorin Y, Abboud HE et al (2010) NAD(P)H oxidase mediates TGF-beta1-induced activation of kidney myofibroblasts. J Am Soc Nephrol 21(1):93-102

42. Maquerlot F, Galiacy S, Malo M, Guignabert C, Lawrence DA, d'Ortho MP et al (2006) Dual role for plasminogen activator inhibitor type 1 as soluble and as matricellular regulator of epithelial alveolar cell wound healing. Am J Pathol 169(5):1624-1632

43. Zavadil J, Bitzer M, Liang D, Yang YC, Massimi A, Kneitz S et al (2001) Genetic programs of epithelial cell plasticity directed by transforming growth factor-beta. Proc Natl Acad Sci USA 98(12):6686-6691

44. Freytag J, Wilkins-Port CE, Higgins CE, Higgins SP, Samarakoon R, Higgins PJ (2010) PAI-1 mediates the TGFbeta1 + EGF-induced "scatter" response in transformed human keratinocytes. J Invest Dermatol 130(9):2179-2190

45. - Sarsour EH, Kumar MG, Chaudhuri L, Kalen AL, Goswami PC (2009) Redox control of the cell cycle in health and disease. Antioxid Redox Signal. 11(12):2985-3011. This article highlights the role of free radicals involved in cell signaling during cell cycle progression particularly focusing on clinical manifestations of fibrosis

46. Menon SG, Sarsour EH, Spitz DR, Higashikubo R, Sturm M, Zhang $\mathrm{H}$ et al (2003) Redox regulation of the G1 to $\mathrm{S}$ phase transition in the mouse embryo fibroblast cell cycle. Cancer Res 63(9):2109-2117

47. Silverberg JI, Patel M, Brody N, Jagdeo J (2012) Caffeine protects human skin fibroblasts from acute reactive oxygen species-induced necrosis. J Drugs Dermatol 11(11):1342-1346

48. Sarsour EH, Venkataraman S, Kalen AL, Oberley LW, Goswami PC (2008) Manganese superoxide dismutase activity regulates transitions between quiescent and proliferative growth. Aging Cell 7(3):405-417

49. Darzynkiewicz Z, Zhao H, Halicka HD, Li J, Lee YS, Hsieh TC et al (2014) In search of antiaging modalities: evaluation of mTOR- and ROS/DNA damage-signaling by cytometry. Cytometry A 85(5):386-399

50. Ladelfa MF, Toledo MF, Laiseca JE, Monte M (2011) Interaction of p53 with tumor suppressive and oncogenic signaling pathways to control cellular reactive oxygen species production. Antioxid Redox Signal 15(6):1749-1761

51. Drane P, Bravard A, Bouvard V, May E (2001) Reciprocal down-regulation of p53 and SOD2 gene expression-implication in p53 mediated apoptosis. Oncogene 20(4):430-439

52. Tobiume K, Matsuzawa A, Takahashi T, Nishitoh H, Morita K, Takeda K et al (2001) ASK1 is required for sustained activations of JNK/p38 MAP kinases and apoptosis. EMBO Rep 2(3): 222-228

53. Ueda S, Masutani H, Nakamura H, Tanaka T, Ueno M, Yodoi J (2002) Redox control of cell death. Antioxid Redox Signal 4(3):405-414

54. Matsukawa J, Matsuzawa A, Takeda K, Ichijo H (2004) The ASK1-MAP kinase cascades in mammalian stress response. J Biochem 136(3):261-265 
55. Kao HF, Chang-Chien PW, Chang WT, Yeh TM, Wang JY (2013) Propolis inhibits TGF-beta1-induced epithelial-mesenchymal transition in human alveolar epithelial cells via PPARgamma activation. Int Immunopharmacol 15(3):565-574

56. Radisky DC, Kenny PA, Bissell MJ (2007) Fibrosis and cancer: do myofibroblasts come also from epithelial cells via EMT? J Cell Biochem 101(4):830-839

57. Rhyu DY, Yang Y, Ha H, Lee GT, Song JS, Uh ST et al (2005) Role of reactive oxygen species in TGF-betal-induced mitogen-activated protein kinase activation and epithelial-mesenchymal transition in renal tubular epithelial cells. J Am Soc Nephrol 16(3):667-675

58. Hinz B, Phan SH, Thannickal VJ, Prunotto M, Desmoulière A, Varga $\mathbf{J}$ et al (2012) Recent developments in myofibroblast biology: paradigms for connective tissue remodeling. Am J Pathol 180(4):1340-1355

59. Grazul-Bilska AT, Johnson ML, Bilski JJ, Redmer DA, Reynolds LP, Abdullah A et al (2003) Wound healing: the role of growth factors. Drugs Today (Barc) 39(10):787-800

60. Haase I, Evans R, Pofahl R, Watt FM (2003) Regulation of keratinocyte shape, migration and wound epithelialization by IGF-1- and EGF-dependent signalling pathways. J Cell Sci 116(Pt 15):3227-3238

61. Chen F, Haigh S, Barman S, Fulton DJ (2012) From form to function: the role of Nox4 in the cardiovascular system. Front Physiol 3:412

62. Siddesha JM, Valente AJ, Sakamuri SS, Gardner JD, Delafontaine P, Noda M et al (2014) Acetylsalicylic acid Inhibits IL-18induced cardiac fibroblast migration through the induction of RECK. J Cell Physiol 229(7):845-855

63. Chiarugi P, Pani G, Giannoni E, Taddei L, Colavitti R, Raugei G et al (2003) Reactive oxygen species as essential mediators of cell adhesion: the oxidative inhibition of a FAK tyrosine phosphatase is required for cell adhesion. J Cell Biol 161(5):933-944

64. Leask A (2013) Integrin $\beta 1$ : a mechanosignaling sensor essential for connective tissue deposition by fibroblasts. Adv Wound Care (New Rochelle) 2(4):160-166

65. Leask A (2013) CCN2: a novel, specific and valid target for antifibrotic drug intervention. Expert Opin Ther Targets 17(9): 1067-1071

66. Pines M, Snyder D, Yarkoni S, Nagler A (2003) Halofuginone to treat fibrosis in chronic graft-versus-host disease and scleroderma. Biol Blood Marrow Transplant 9(7):417-425

67. Keeley F, Murray R (2011) The Extracellular matrix. In: Bender D, Botham K, Weil P, Kennelly P, Murray R, Rodwell V (eds) Harper's illustrated biochemistry, 29th edn. McGraw-Hill, New York

68. Bell SA, Faust H, Mittermüller J, Kolb HJ, Meurer M (1996) Specificity of antinuclear antibodies in scleroderma-like chronic graft-versus-host disease: clinical correlation and histocompatibility locus antigen association. Br J Dermatol 134(5):848-854

69. Kavian N, Marut W, Servettaz A, Laude H, Nicco C, Chereau C et al (2012) Arsenic trioxide prevents murine sclerodermatous graft-versus-host disease. J Immunol 188(10):5142-5149

70. Yamamoto $T$ (2006) The bleomycin-induced scleroderma model: what have we learned for scleroderma pathogenesis? Arch Dermatol Res 297(8):333-344

71. Svegliati S, Olivieri A, Campelli N, Luchetti M, Poloni A, Trappolini S et al (2007) Stimulatory autoantibodies to PDGF receptor in patients with extensive chronic graft-versus-host disease. Blood 110(1):237-241

72. Marut WK, Kavian N, Servettaz A, Nicco C, Ba LA, Doering M et al (2012) The organotelluride catalyst (PHTE)(2)NQ prevents $\mathrm{HOCl}$-induced systemic sclerosis in mouse. J Invest Dermatol 132(4):1125-1132

73. Kim JS, Choi IG, Lee BC, Park JB, Kim JH, Jeong JH et al (2012) Neuregulin induces CTGF expression in hypertrophic scarring fibroblasts. Mol Cell Biochem 365(1-2):181-189
74. Wan KC, Evans JH (1999) Free radical involvement in hypertrophic scar formation. Free Radic Biol Med 26(5-6):603-608

75. De Felice B, Garbi C, Santoriello M, Santillo A, Wilson RR (2009) Differential apoptosis markers in human keloids and hypertrophic scars fibroblasts. Mol Cell Biochem 327(1-2):191-201

76. Wu JG, Ma L, Zhang SY, Zhu ZZ, Zhang H, Qin LP et al (2011) Essential oil from rhizomes of Ligusticum chuanxiong induces apoptosis in hypertrophic scar fibroblasts. Pharm Biol 49(1): $86-93$

77. Panchatcharam M, Miriyala S, Gayathri VS, Suguna L (2006) Curcumin improves wound healing by modulating collagen and decreasing reactive oxygen species. Mol Cell Biochem 290(1-2):87-96

78. Jagetia GC, Rajanikant GK (2004) Role of curcumin, a naturally occurring phenolic compound of turmeric in accelerating the repair of excision wound, in mice whole-body exposed to various doses of gamma-radiation. J Surg Res 120(1):127-138

79. Scharstuhl A, Mutsaers HA, Pennings SW, Szarek WA, Russel FG, Wagener FA (2009) Curcumin-induced fibroblast apoptosis and in vitro wound contraction are regulated by antioxidants and heme oxygenase: implications for scar formation. J Cell Mol Med 13(4):712-725

80. Zeng G, Zhong F, Li J, Luo S, Zhang P (2013) Resveratrolmediated reduction of collagen by inhibiting proliferation and producing apoptosis in human hypertrophic scar fibroblasts. Biosci Biotechnol Biochem 77(12):2389-2396

81. Ikeda K, Torigoe T, Matsumoto Y, Fujita T, Sato N, Yotsuyanagi $T$ (2013) Resveratrol inhibits fibrogenesis and induces apoptosis in keloid fibroblasts. Wound repair and regeneration : official publication of the Wound Healing Society [and] the European Tissue Repair. Society 21(4):616-623

82. Inaba K, Steinman RM (1984) Resting and sensitized T lymphocytes exhibit distinct stimulatory (antigen-presenting cell) requirements for growth and lymphokine release. J Exp Med 160(6): 1717-1735

83. Wagner B, Tan C, Barnes JL, Ahuja S, Davis TL, Gorin Y et al (2012) Nephrogenic systemic fibrosis: evidence for oxidative stress and bone marrow-derived fibrocytes in skin, liver, and heart lesions using a 5/6 nephrectomy rodent model. Am J Pathol 181(6):1941-1952

84. Ogawa F, Shimizu K, Muroi E, Hara T, Sato S (2011) Increasing levels of serum antioxidant status, total antioxidant power, in systemic sclerosis. Clin Rheumatol 30(7):921-925

85. Andersen GN, Caidahl K, Kazzam E, Petersson AS, Waldenström A, Mincheva-Nilsson L et al (2000) Correlation between increased nitric oxide production and markers of endothelial activation in systemic sclerosis: findings with the soluble adhesion molecules E-selectin, intercellular adhesion molecule 1, and vascular cell adhesion molecule 1. Arthritis Rheum 43(5):1085-1093

86. Cotton SA, Herrick AL, Jayson MI, Freemont AJ (1999) Endothelial expression of nitric oxide synthases and nitrotyrosine in systemic sclerosis skin. J Pathol 189(2):273-278

87. Dooley A, Gao B, Bradley N, Abraham DJ, Black CM, Jacobs $\mathrm{M}$ et al (2006) Abnormal nitric oxide metabolism in systemic sclerosis: increased levels of nitrated proteins and asymmetric dimethylarginine. Rheumatology (Oxford) 45(6):676-684

88. Sambo P, Baroni SS, Luchetti M, Paroncini P, Dusi S, Orlandini $\mathrm{G}$ et al (2001) Oxidative stress in scleroderma: maintenance of scleroderma fibroblast phenotype by the constitutive up-regulation of reactive oxygen species generation through the NADPH oxidase complex pathway. Arthritis Rheum 44(11): 2653-2664

89. Yamamoto T, Katayama I, Nishioka K (1998) Nitric oxide production and inducible nitric oxide synthase expression in systemic sclerosis. J Rheumatol 25(2):314-317 
90. Sambo P, Jannino L, Candela M, Salvi A, Donini M, Dusi S et al (1999) Monocytes of patients with systemic sclerosis (scleroderma) spontaneously release in vitro increased amounts of superoxide anion. J Invest Dermatol 112(1):78-84

91. Dooley A, Bruckdorfer KR, Abraham DJ (2012) Modulation of fibrosis in systemic sclerosis by nitric oxide and antioxidants. Cardiol Res Pract 2012:521958

92. Bagnato G, Bitto A, Pizzino G, Irrera N, Sangari D, Cinquegrani $M$ et al (2013) Simvastatin attenuates the development of pulmonary and cutaneous fibrosis in a murine model of systemic sclerosis. Rheumatology (Oxford) 52(8):1377-1386

93. Bagnato G, Bitto A, Irrera N, Pizzino G, Sangari D, Cinquegrani $\mathrm{M}$ et al (2013) Propylthiouracil prevents cutaneous and pulmonary fibrosis in the reactive oxygen species murine model of systemic sclerosis. Arthritis Res Ther 15(5):R120

94. Kavian N, Marut W, Servettaz A, Nicco C, Chereau C, Lemarechal $\mathrm{H}$ et al (2012) Reactive oxygen species-mediated killing of activated fibroblasts by arsenic trioxide ameliorates fibrosis in a murine model of systemic sclerosis. Arthritis Rheum 64(10):3430-3440

95. Zhou CF, Yu JF, Zhang JX, Jiang T, Xu SH, Yu QY et al (2013) $\mathrm{N}$-acetylcysteine attenuates subcutaneous administration of bleomycin-induced skin fibrosis and oxidative stress in a mouse model of scleroderma. Clin Exp Dermatol 38(4):403-409
96. Yoshizaki A, Yanaba K, Ogawa A, Iwata Y, Ogawa F, Takenaka $\mathrm{M}$ et al (2011) The specific free radical scavenger edaravone suppresses fibrosis in the bleomycin-induced and tight skin mouse models of systemic sclerosis. Arthritis Rheum 63(10): 3086-3097

97. Rudolf E, Cervinka M (2009) Trivalent chromium activates Rac-1 and Src and induces switch in the cell death mode in human dermal fibroblasts. Toxicol Lett 188(3):236-242

98. Cracowski JL, Girolet S, Imbert B, Seinturier C, Stanke-Labesque F, Bessard J et al (2005) Effects of short-term treatment with vitamin $\mathrm{E}$ in systemic sclerosis: a double blind, randomized, controlled clinical trial of efficacy based on urinary isoprostane measurement. Free Radic Biol Med 38(1):98-103

99. Mavrikakis ME, Lekakis JP, Papamichael CM, Stamatelopoulos KS, Kostopoulos CC, Stamatelopoulos SF (2003) Ascorbic acid does not improve endothelium-dependent flow-mediated dilatation of the brachial artery in patients with Raynaud's phenomenon secondary to systemic sclerosis. Int J Vitam Nutr Res 73(1):3-7

100. Lee HB, Ha H (2007) Mechanisms of epithelial-mesenchymal transition of peritoneal mesothelial cells during peritoneal dialysis. J Korean Med Sci 22(6):943-945 